\title{
Patterns of recurrent and persistent intestinal metaplasia after successful radiofrequency ablation of Barrett's esophagus
}

\author{
Robert J. Korst, MD, ${ }^{\text {a,b }}$ Sobeida Santana-Joseph, MSN,,${ }^{\text {ab }}$ John R. Rutledge, MAS, ${ }^{\text {a }}$ Arthur Antler, MD, ${ }^{\mathrm{c}}$ \\ Vivian Bethala, MD ${ }^{\mathrm{c}}$ Anthony DeLillo, MD, ${ }^{\mathrm{c}}$ Donald Kutner, DO, ${ }^{\mathrm{c}}$ Benjamin E. Lee, MD, ${ }^{\mathrm{a}, \mathrm{b}}$ \\ Haleh Pazwash, MD, ${ }^{\mathrm{c}}$ Robert H. Pittman, MD ${ }^{\mathrm{c}}$ Michael Rahmin, MD, ${ }^{\mathrm{c}}$ and Mitchell Rubinoff, $\mathrm{MD}^{\mathrm{c}}$
}

Objective: Radiofrequency ablation can eradicate Barrett's esophagus successfully in the majority of cases. We sought to determine (1) how often intestinal metaplasia is detected during follow-up endoscopy after successful ablation and (2) patterns of persistent/recurrent intestinal metaplasia.

\begin{abstract}
Methods: Patients ablated successfully during a phase II clinical trial of radiofrequency ablation for Barrett's esophagus were followed using endoscopic surveillance according to a defined protocol. Systematic biopsies were performed in all patients throughout the neosquamous epithelium as well as at the gastroesophageal junction, and patterns of recurrent or persistent intestinal metaplasia were documented.

Results: Fifty-three patients were ablated successfully during this single-institution clinical trial. A total of 151 follow-up endoscopies were performed (range, 1-5 endoscopies per patient) and 2492 biopsies were obtained, of which 604 (24\%) were from the gastroesophageal junction. The median follow-up period was 18 months (range, 3-50 months). Recurrent/persistent intestinal metaplasia was detected in 14 patients (26\%) in 3 distinct patterns: endoscopically invisible intestinal metaplasia underneath the neosquamous epithelium (buried glands) in 3 patients, visible recurrence in the tubular esophagus in 3 patients, and intestinal metaplasia of the gastroesophageal junction (with a squamous-lined tubular esophagus) in 10 patients. Dysplasia or cancer was not detected in any patient during the follow-up period.
\end{abstract}

Conclusions: Recurrent/persistent intestinal metaplasia after successful radiofrequency ablation of Barrett's esophagus is relatively common. This finding has implications for the continued surveillance of patients who are ablated successfully. (J Thorac Cardiovasc Surg 2013;145:1529-34)

Earn CME credits at

http://cme.ctsnetjournals.org

Radiofrequency ablation (RFA) is established as an effective procedure for the eradication of Barrett's esophagus (BE). ${ }^{1,2}$ Success rates using this technology have been reported to range from $40 \%$ to $100 \%$ for the elimination of intestinal metaplasia (IM) from the tubular esophagus. ${ }^{1-11}$ Furthermore, complication rates are low, and a recent, randomized clinical trial has demonstrated that the successful use of RFA prevents the development

\footnotetext{
From The Daniel and Gloria Blumenthal Cancer Center, ${ }^{\text {a }}$ Paramus, NJ; and the Division of Thoracic Surgery, ${ }^{\mathrm{b}}$ Department of Surgery, and the Division of Gastroenterology, ${ }^{\mathrm{c}}$ Department of Medicine, The Valley Hospital/Valley Health System, Ridgewood, NJ.

Disclosures: Authors have nothing to disclose with regard to commercial support. Received for publication June 7, 2012; revisions received Oct 5, 2012; accepted for publication Nov 6, 2012; available ahead of print Dec 10, 2012.

Address for reprints: Robert J. Korst, MD, The Daniel and Gloria Blumenthal Cancer Center, The Valley Hospital/Valley Health System, 1 Valley Health Plaza, Paramus, NJ 07652 (E-mail: korsro@valleyhealth.com).

$0022-5223 / \$ 36.00$

Copyright (c) 2013 by The American Association for Thoracic Surgery

http://dx.doi.org/10.1016/j.jtcvs.2012.11.016
}

of esophageal carcinoma in patients with dysplastic BE. ${ }^{1}$ Despite these advantages, the majority of patients require multiple treatment sessions, especially those with long columnar segments and large hiatal hernias. ${ }^{12}$

After successful ablation of BE, it becomes potentially important to determine whether IM persists in some fashion or recurs, because IM is thought to be the premalignant lesion in BE. ${ }^{13}$ Histologic assessment of the post-RFA esophagus is performed by surveillance endoscopy with systematic biopsies of the neosquamous epithelium. Although IM after ablation has been reported to occur in the form of buried glands (representing persistent IM) - in which glandular mucosa underlies stratified squamous epithelium, giving the endoscopic appearance of a grossly normal esophagus ${ }^{14}$ - the phenomenon of actual recurrence of $\mathrm{BE}$ is not well described. In addition, a paucity of published data exist regarding the histologic state of the gastroesophageal junction after RFA in the tubular esophagus, with a single retrospective study addressing this issue specifically. ${ }^{15}$ Given the lack of information regarding persistent IM, recurrent IM, and the histologic state of the gastroesophageal junction after RFA, the current study characterizes these phenomena using follow-up from a prospective clinical trial that evaluated RFA for BE. 


\section{Abbreviations and Acronyms \\ $\mathrm{BE}=$ Barrett's esophagus \\ $\mathrm{IM}=$ intestinal metaplasia \\ PPI $=$ proton pump inhibitor \\ $\mathrm{RFA}=$ radiofrequency ablation}

\section{METHODS \\ Clinical Trial}

A phase II clinical trial of RFA for BE was performed between 2007 and 2011 at a single institution after approval by the institutional review board. All patients signed informed consent. Barrett's esophagus was defined as an esophageal columnar segment $>3 \mathrm{~cm}$ in length regardless of whether IM was detected by biopsy or an esophageal columnar segment $<3 \mathrm{~cm}$ with biopsy-proved IM. Patients with IM of the gastroesophageal junction without a columnar-lined esophagus were not included in this trial. The initial success rates of eradicating BE were published previously, along with the clinical trial details. ${ }^{12}$ Success was defined as establishment of squamous epithelium (confirmed histologically) throughout the tubular esophagus as visualized using both white light and narrow-band imaging. Two months after the last ablation, all patients underwent a single follow-up endoscopy, during which the success of the procedure was established. This initial follow-up endoscopy was not considered part of the follow-up protocol. As part of the clinical trial, all successfully ablated patients underwent scheduled endoscopic follow-up according to a rigorous protocol depending on patients' preablation histologic diagnosis, as shown in Table 1. During each endoscopy, inspection of the mucosa was performed using white light and narrow-band imaging, and systematic biopsies were performed. Successfully ablated patients who had IM discovered at the gastroesophageal junction (cardia) at follow-up endoscopy did not undergo further ablation because they did not meet the definition of BE established when the protocol was written.

After successful RFA, a proton pump inhibitor (PPI) dose was maintained at a level that provided relief from gastroesophageal reflux symptoms. The performance of hiatal hernia repair and fundoplication was left up to the discretion of the principal investigator (R.J.K.), but was mainly symptom directed.

\section{Biopsy Protocol}

At each endoscopic examination, a systematic biopsy protocol was followed in all patients, which included 4 quadrant biopsies, performed at 1 to 2-cm intervals throughout the entire segment of neosquamous epithelium using jumbo biopsy forceps (Radial jaw 4; Boston Scientific, Natick, Mass). In addition, 4 quadrant biopsies were performed routinely just inferior to the "new" squamocolumnar junction (the gastroesophageal junction). If, at the time of endoscopic examination, a significant region of mucosal irregularity was identified in a columnar-lined area, it was removed using endoscopic mucosal resection. Biopsy specimens were fixed in formalin, embedded in paraffin, cut, and stained with hematoxylin and eosin.

\section{Data Collection}

Data collected for the current analysis included patient demographics, length of BE, size of hiatal hernia, number of post-RFA endoscopies, number of post-RFA biopsies, length of follow-up after the last ablation, recurrence of BE, the presence of buried glands, and the presence of IM with or without dysplasia of the gastroesophageal junction. Recurrent BE was defined as the recurrence of a grossly visible columnar lining within the tubular esophagus, with histologic confirmation of IM. Buried glands were defined as glandular epithelium present underneath stratified squamous epithelium.

\section{Statistical Analysis}

Follow-up data were analyzed using the Kaplan-Meier methodology, and the probability of being recurrence free was plotted. IBM-SPSS Statistics software (version 19; Armonk, NY) was used for the statistical analysis.

\section{RESULTS \\ Patient Characteristics}

Fifty-three patients were treated successfully using RFA for BE on this phase II protocol. There were 37 males and 16 females, with a median age of 59 years (age range, 24-85 years). The median length of the initial columnar segment was $3 \mathrm{~cm}$ (range, $1-16 \mathrm{~cm}$ ) and the median hiatal hernia size was $2 \mathrm{~cm}$ (range, $0-8 \mathrm{~cm}$ ). Forty patients $(75 \%)$ had nondysplastic $\mathrm{BE}$, whereas 4 patients $(8 \%)$ had low-grade dysplasia, $4(8 \%)$ had high-grade dysplasia, and $4(8 \%)$ were read as indefinite for dysplasia. One patient had a T1a adenocarcinoma removed using endoscopic mucosal resection prior to RFA for the remaining BE. All patients had IM present in their columnar segments prior to ablation.

\section{Endoscopic Follow-up}

A total of 151 follow-up endoscopies were performed on this cohort of 53 patients (median, 3 per patient; range, 1-5 per patient) and a total of 2492 biopsies were evaluated histologically (median, 36 per patient; range, 8-156 per patient). Biopsies obtained from the gastroesophageal junction totaled 604 (24\% of total biopsies). The median follow-up period was 18 months (range, 3-50 months). Figure 1 demonstrates follow-up compliance for the 51 patients who entered the follow-up protocol. Two patients have been ablated successfully but have not yet undergone their first endoscopy in the follow-up protocol. Recurrent and/or persistent IM was detected at some point during the follow-up period in 14 of 53 successfully ablated patients $(26 \%)$. Figure 2 demonstrates the probability of being recurrence free based on the follow-up data.

\section{Buried Glands}

Buried glands were detected at some point after successful ablation in 3 biopsies from 3 patients ( $6 \%$ of patients, $0.2 \%$ of biopsies from the tubular esophagus). All 3 patients had at least 3 post-RFA endoscopies, and in no patient was dysplasia detected. The clinical characteristics of these 3 patients are displayed in Table 2.

\section{Recurrence of Barrett's Esophagus}

Recurrent BE was detected endoscopically and confirmed histologically in 3 patients $(6 \%)$. In all 3 instances, new tongues of columnar lining ( $1-2 \mathrm{~cm}$ in length) were visualized in the presence of active esophagitis, and biopsies confirmed IM, without dysplasia. After their successful initial ablation, 
TABLE 1. Follow-up protocol after successful ablation

\begin{tabular}{lc}
\hline Preablation histologic diagnosis & Endoscopy interval \\
\hline BE, but no dysplasia & $\begin{array}{c}\text { Every } 6 \text { months for } 1 \text { year, then } \\
\text { every year for } 2 \text { years, then every } \\
2 \text { years }\end{array}$ \\
$\begin{array}{cc}\text { BE with either low-grade dysplasia, } \\
\text { or indeterminate for dysplasia }\end{array}$ & $\begin{array}{c}\text { Every months for } 2 \text { years, then } \\
\text { every year for } 2 \text { years, then every }\end{array}$ \\
$\begin{array}{c}\text { High-grade dysplasia or T1a } \\
\text { carcinoma }\end{array}$ & $\begin{array}{l}\text { Every } 3 \text { months for } 1 \text { year, then } \\
\text { every } 6 \text { months for } 3 \text { years, then } \\
\end{array}$ \\
\hline
\end{tabular}

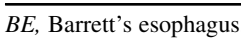

all 3 patients had lowered their PPI dose to the dose they were taking prior to ablation. The clinical characteristics of these 3 patients are shown in Table 3.

\section{Intestinal Metaplasia of the Gastroesophageal Junction}

After successful ablation, 10 patients (19\%) were diagnosed with IM of the gastroesophageal junction, despite having a squamous-lined tubular esophagus. Dysplasia was not detected in any patient. Table 4 presents the clinical characteristics and persistence of IM of the gastroesophageal junction in these 10 patients. Nine of these patients were ablated initially for nondysplastic BE, with the 10th patient having high-grade dysplasia prior to ablation.

\section{Postablation Gastroesophageal Reflux Control}

After successful ablation, 15 patients $(28 \%)$ decreased their PPI dose down to the level they were taking prior to ablation. Thirty-four patients $(64 \%)$ were maintained on the elevated PPI dose used for ablation. Four patients $(8 \%)$ underwent hiatal hernia repair and fundoplication.

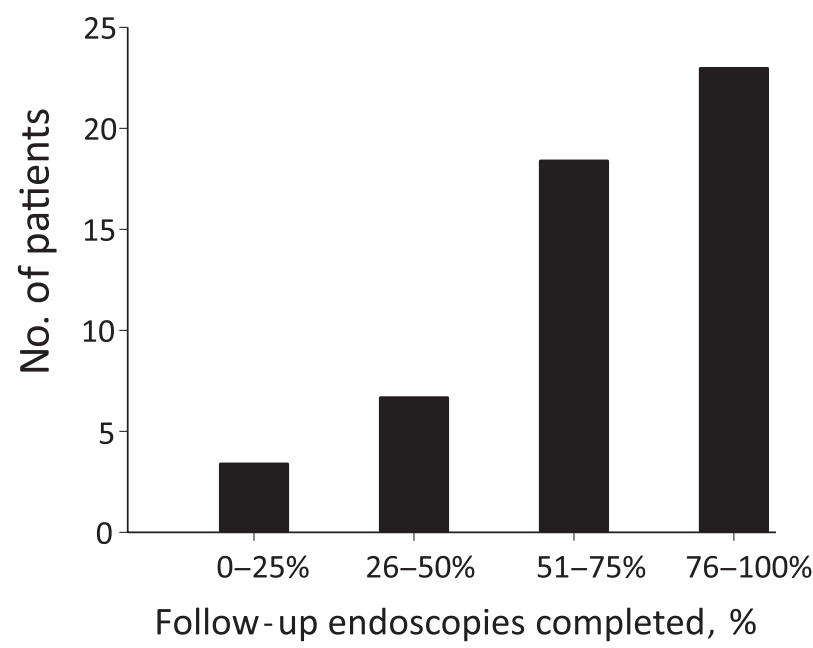

FIGURE 1. Adherence to the follow-up protocol for 51 successfully ablated patients. Two recently successfully ablated patients have not yet entered the follow-up protocol.

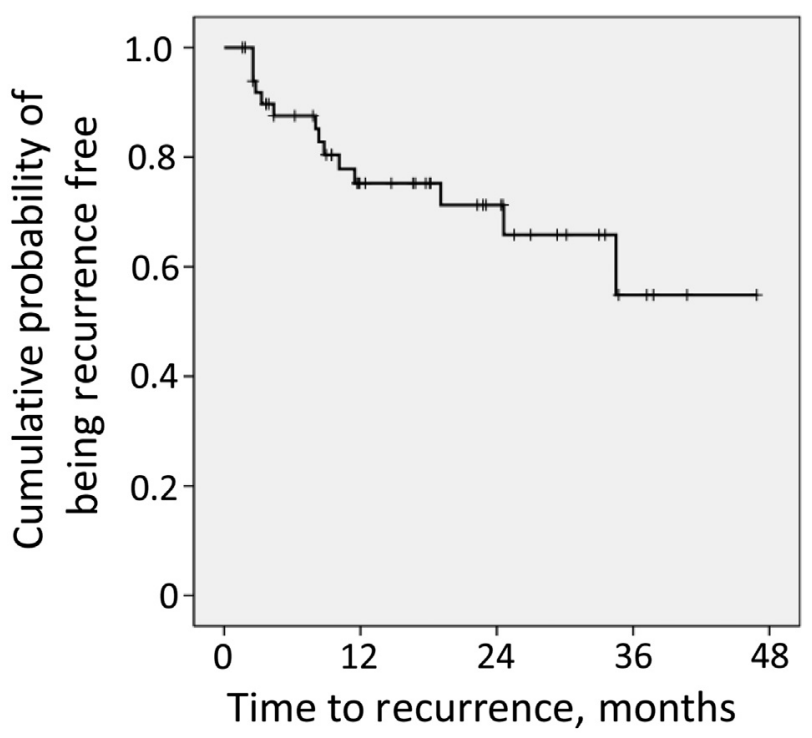

FIGURE 2. Kaplan-Meier analysis demonstrating the cumulative probability of being recurrence free from intestinal metaplasia after successful radiofrequency ablation of Barrett's esophagus.

Two were performed after successful ablation, 1 was performed prior to any ablation attempts, and the 4th was performed after an initial attempt at ablation failed to heal with squamous mucosa. This last patient then underwent successful ablation after his fundoplication. These 4 patients eliminated their regular PPI use after successful ablation. The patient who underwent hernial repair prior to ablation had recurrence of IM in the form of buried glands as well as IM of the gastroesophageal junction (Tables 2 and 4, patient no. 006).

\section{DISCUSSION}

Barrett's esophagus is a premalignant condition of the esophagus caused by chronic gastroesophageal reflux. The risk of developing adenocarcinoma of the esophagus in the setting of $\mathrm{BE}$ is not clear, but estimates have ranged from $0.1 \%$ to $0.5 \%$ per patient, per year of follow-up, with the risk being cumulative over time. ${ }^{16}$ As a result, ablative techniques have been developed aimed at eliminating the columnar lining and replacing it with stratified squamous epithelium. We have published previously our initial results with eradication of BE using RFA from a phase II clinical trial at our institution conducted between 2007 and 2011, with an intent-to-treat success rate of $78 \%$ (91\% "per protocol" success rate). ${ }^{12}$ The current analysis addresses the follow-up of the successfully ablated patients from this clinical trial, focusing on the persistence and recurrence of IM.

\section{Intestinal Metaplasia in the Postablation Tubular Esophagus}

In the current study, IM of the tubular esophagus detected during the follow-up period took 2 forms: buried glands 
TABLE 2. Clinical features of patients with buried glands found after successful ablation

\begin{tabular}{|c|c|c|c|c|c|c|c|c|c|}
\hline \multirow[b]{2}{*}{ Patient no. } & \multirow[b]{2}{*}{$\begin{array}{c}\text { Preablation } \\
\text { histology }\end{array}$} & \multirow[b]{2}{*}{$\begin{array}{l}\text { Initial BE } \\
\text { length, cm }\end{array}$} & \multirow[b]{2}{*}{$\begin{array}{l}\text { Level of buried } \\
\text { glands, cm* }\end{array}$} & \multirow{2}{*}{$\begin{array}{l}\text { Level of "new" } \\
\text { squamocolumnar } \\
\text { junction, cm* }\end{array}$} & \multicolumn{5}{|c|}{ Timing of positive endoscopy $\dagger$} \\
\hline & & & & & 1st & 2nd & 3rd & 4th & 5th \\
\hline 007 & HGD & 10 & 36 & 40 & $\mathrm{~N}$ & $\mathrm{~N}$ & $\mathrm{~N}$ & $\mathrm{~N}$ & $\mathrm{Y}$ \\
\hline 006 & Nondysplastic & 16 & 38 & 42 & $\mathrm{~N}$ & $\mathrm{Y}$ & $\mathrm{N}$ & NP & $\mathrm{N}$ \\
\hline 017 & Nondysplastic & 5 & 26 & 30 & $\mathrm{Y}$ & $\mathrm{N}$ & $\mathrm{N}$ & - & - \\
\hline
\end{tabular}

$B E$, Barrett's esophagus; $H G D$, high-grade dysplasia; $N$, buried glands not detected; $Y$, buried glands detected; $N P$, endoscopy at designated time interval was not performed; follow-up time point has not yet been reached. *Distance from incisors. †Postablation endoscopies were performed according to the schedule in Table 1.

(endoscopically invisible subsquamous IM) as well as recurrent tongues of endoscopically visible columnar lining. Buried glands have been reported in patients with BE both before and after attempts at ablation, regardless of the ablative technique used. ${ }^{14,17}$ In the presence of $\mathrm{BE}$, buried glands are usually associated with squamous islands located within the columnar segment. ${ }^{17}$ Indeed, in the randomized trial of RFA for dysplastic BE, Shaheen and colleagues ${ }^{1}$ found buried glands in $25.2 \%$ of patients prior to treatment randomization. In contrast, buried glands were not detected in any patient from the current study prior to ablation, perhaps because the protocol did not mandate routine sampling of the squamous mucosa prior to ablation.

Buried glands after RFA are uncommon, and have been found in less than $10 \%$ of patients enrolled in clinical trials evaluating RFA. ${ }^{1-11}$ Results from the clinical trial reported herein corroborate this finding, with only $6 \%$ of successfully ablated patients demonstrating this phenomenon at some point during their follow-up. Interestingly, all biopsies showing buried glands were located a substantial distance away from any visible columnar mucosa (Table 2). Although buried glandular tissue has been reported to harbor dysplasia and even malignancy, ${ }^{14}$ this was not the case in the current study.

Visible recurrence of BE in the tubular esophagus after successful RFA has been described only vaguely. Existing reports describe recurrences in the region of the gastroesophageal junction, making it difficult to discern whether these cases represent actual recurrence in the esophagus or simply IM of the gastroesophageal junction in the presence of a visibly normal tubular esophagus. ${ }^{1,2}$ In the current study, 3 clear-cut recurrences were detected, in which new tongues of columnar lining were identified in the tubular esophagus. All cases occurred in patients who had lowered their PPI dose back down to their preablation dose (which had been doubled for the duration of the ablation sessions). In addition, all 3 cases were associated with the presence of endoscopically visible esophagitis. Whether successfully ablated patients should be maintained at a higher PPI dose after RFA remains to be determined, but this represents a relevant question based on these results.

\section{Intestinal Metaplasia of the Gastroesophageal Junction}

The most common circumstance in which IM was detected after successful RFA of the tubular esophagus in the current trial was immediately inferior to the "new" squamocolumnar junction (cardia of stomach). Because the protocol mandated the routine that 4 quadrant biopsies be acquired in this region using jumbo forceps, every patient's gastroesophageal junction was evaluated during every postablation endoscopic examination. There is a paucity of prospective, published data addressing this phenomenon because routine sampling of this area was not performed in several of the clinical trials evaluating RFA for BE. ${ }^{1,2,6}$ In the prospective trials in which it was evaluated, IM of the gastroesophageal junction was not as frequent as described herein $(19 \%$ of successfully ablated patients), ranging from $0 \%$ to $18 \%$ of patients. ${ }^{3-5}$ The $19 \%$ frequency described in the current study, however, supports the retrospective analysis performed by Vaccaro and colleagues, ${ }^{15}$ in which IM of the gastroesophageal junction was detected in 11 of 49 successfully ablated patients $(22 \%)$.

The significance of IM of the gastroesophageal junction detected in patients in whom the tubular esophagus has been ablated successfully using RFA is unknown. It is unclear whether these patients developed recurrent IM in this area or whether this finding represents persistent IM, because the cardia was not ablated in this trial. Intestinal

TABLE 3. Clinical features of patients with recurrent Barrett's esophagus with intestinal metaplasia

\begin{tabular}{|c|c|c|c|c|c|c|c|c|}
\hline \multirow[b]{2}{*}{ Patient no. } & \multirow[b]{2}{*}{ Preablation histology } & \multirow[b]{2}{*}{ Initial BE length, cm } & \multirow[b]{2}{*}{ Size of hiatal hernia, $\mathrm{cm}^{*}$} & \multicolumn{5}{|c|}{ Timing of positive endoscopy $\dagger$} \\
\hline & & & & 1st & 2nd & 3rd & 4th & 5th \\
\hline 023 & Nondysplastic & 4 & 4 & $\mathrm{~N}$ & $\mathrm{~N}$ & NP & $\mathrm{Y}$ & - \\
\hline 053 & Nondysplastic & 2 & 5 & $\mathrm{~N}$ & NP & $\mathrm{Y}$ & $\mathrm{N}$ & - \\
\hline 028 & Nondysplastic & 5 & 8 & $\mathrm{Y}$ & $\mathrm{N}$ & $\mathrm{N}$ & - & - \\
\hline
\end{tabular}

$B E$, Barrett's esophagus; $N$, recurrence not detected; $N P$, endoscopy at designated time interval was not performed; $Y$, recurrence detected; —, follow-up time point has not yet been reached. *Distance between the top of the gastric folds and the crural pinch. †Postablation endoscopies were performed according to the schedule in Table 1. 
TABLE 4. Clinical features of patients with intestinal metaplasia of the gastroesophageal junction detected after successful radiofrequency ablation

\begin{tabular}{|c|c|c|c|c|c|c|c|c|}
\hline \multirow[b]{2}{*}{ Patient no. } & \multirow[b]{2}{*}{ Preablation histology } & \multirow[b]{2}{*}{ Initial BE length, cm } & \multirow[b]{2}{*}{ Size of hiatal hernia, cm* } & \multicolumn{5}{|c|}{ Timing of positive endoscopy $\dagger$} \\
\hline & & & & 1st & 2nd & 3rd & 4th & 5th \\
\hline 009 & Nondysplastic & 1 & 0 & $\mathrm{~N}$ & $\mathrm{Y}$ & $\mathrm{N}$ & $\mathrm{N}$ & - \\
\hline 036 & Nondysplastic & 1 & 2 & $\mathrm{~N}$ & $\mathrm{~N}$ & $\mathrm{Y}$ & $\mathrm{Y}$ & - \\
\hline 042 & Nondysplastic & 6 & 4 & $\mathrm{Y}$ & $\mathrm{N}$ & $\mathrm{N}$ & - & - \\
\hline 024 & Nondysplastic & 2 & 0 & $\mathrm{~N}$ & $\mathrm{Y}$ & $\mathrm{Y}$ & $\mathrm{N}$ & $\mathrm{N}$ \\
\hline 059 & Nondysplastic & 2 & 3 & $\mathrm{Y}$ & $\mathrm{N}$ & $\mathrm{N}$ & $\mathrm{Y}$ & - \\
\hline 069 & Nondysplastic & 3 & 3 & $\mathrm{Y}$ & $\mathrm{N}$ & $\mathrm{N}$ & - & - \\
\hline 007 & HGD & 10 & 2 & $\mathrm{~N}$ & $\mathrm{~N}$ & Y & $\mathrm{N}$ & $\mathrm{N}$ \\
\hline 081 & Nondysplastic & 3 & 0 & $\mathrm{Y}$ & $\mathrm{N}$ & $\mathrm{Y}$ & - & - \\
\hline 094 & Nondysplastic & 2 & 2 & $\mathrm{Y}$ & $\mathrm{N}$ & & - & - \\
\hline 006 & Nondysplastic & 16 & 2 & $\mathrm{Y}$ & $\mathrm{Y}$ & $\mathrm{Y}$ & NP & $\mathrm{Y}$ \\
\hline
\end{tabular}

$B E$, Barrett's esophagus; $N$, intestinal metaplasia of the gastroesophageal junction is not detected; $Y$, intestinal metaplasia of the gastroesophageal junction is detected; follow-up time point has not yet been reached; $H G D$, high-grade dysplasia; $N P$, endoscopy at designated time interval was not performed. *Distance between the top of the gastric folds and the crural pinch. †Postablation endoscopies were performed according to the schedule in Table 1.

metaplasia of the gastroesophageal junction is a common finding in patients without BE who undergo upper endoscopy for nonreflux-related reasons. ${ }^{18}$ Although the malignant potential of this finding in such patients is unclear, causally it seems to be related to chronic inflammation. Whether this inflammation is a result of gastroesophageal reflux, Helicobacter pylori infection, or other factors remains controversial. ${ }^{19}$ A potential shortcoming of this clinical trial is that patients did not have routine, preablation biopsies of the distal stomach evaluating for $H$ pylori infection, although given the advanced state of their gastroesophageal reflux, it seems unlikely that Helicobacter-induced IM of the stomach would have been a significant contributor. The significance of IM of the gastroesophageal junction detected in the postablation setting is completely unknown and may represent a completely different lesion than that found de novo in the absence of BE. Given the absence of data, the proper course of action is unclear. Options include continued RFA of the gastroesophageal junction and cardia, continued surveillance with systematic biopsies, or no further treatment/surveillance.

\section{Ablation of Nondysplastic Barrett's Esophagus}

The current study was conducted in the context of a phase II clinical trial, with the majority of patients having nondysplastic BE. It is currently controversial whether nondysplastic patients should be offered RFA outside a clinical trial setting. Because of the low risk of nondysplastic patients (as a group) progressing to adenocarcinoma, it has been argued that RFA represents overtreatment for these patients. ${ }^{20}$ The counterargument, however, states that RFA for nondysplastic patients should be individualized, because the malignant risk may not be the same for all nondysplastic segments, because RFA is such a safe technology, and because the alternative of surveillance endoscopy with biopsies has proven shortcomings. ${ }^{21}$ Until further prognostic information is obtained, this issue will remain controversial.

\section{CONCLUSIONS}

The detection of IM after successful RFA of BE is common, occurring in $26 \%$ of individuals treated with this technology. Although the incidence of buried glands and endoscopically visible recurrence of IM is uncommon, the presence of IM of the gastroesophageal junction is encountered more frequently-the significance of which is unknown-but has implications for further surveillance after successful RFA.

\section{References}

1. Shaheen NJ, Sharma P, Overholt BF, Wolfsen HC, Sampliner RE, Wang KK, et al. Radiofrequency ablation in Barrett's esophagus with dysplasia. $N$ Engl J Med. 2009;360:2277-88.

2. Fleischer DE, Overholt BF, Sharma VK, Reymunde A, Kimmey MB, Chang KJ, et al. Endoscopic radiofrequency ablation for Barrett's esophagus: 5-year outcomes from a prospective multicenter trial. Endoscopy. 2010;42:781-9.

3. Pouw RE, Wirths K, Eisendrath P, Sondermeijer CM, Ten Kate FJ, Fockens P, et al. Efficacy of radiofrequency ablation combined with endoscopic resection for Barrett's esophagus with early neoplasia. Clin Gastroenterol Hepatol. 2010;8:23-9.

4. Van Vilsteren FGI, Pouw RE, Seewald S, Herrero LA, Sondermeijer CMT, Visser M, et al. Stepwise radical endoscopic resection versus radiofrequency ablation for Barrett's esophagus with high grade dysplasia or early cancer: a multicenter randomized trial. Gut. 2011;60:765-73.

5. Hernandez JC, Reicher S, Chung D, Pham BV, Tsai F, Disibio G, et al. Pilot series of radiofrequency ablation of Barrett's esophagus with or without neoplasia. Endoscopy. 2008;40:388-92.

6. Roorda AK, Marcus SN, Triadafilopoulos G. Early experience with radiofrequency energy ablation therapy for Barrett's esophagus with and without dysplasia. Dis Esophagus. 2007;20:516-22.

7. Gundrie JJ, Pouw RE, Sondermeijer CM, Peters FP, Curvers WL, Rosmolen WD, et al. Stepwise circumferential and focal ablation of Barrett's esophagus with high-grade dysplasia: results of the first prospective series of 11 patients. Endoscopy. 2008;40:359-69.

8. Ganz RA, Overholt BF, Sharma VK, Fleischer DE, Shaheen NJ, Lightdale CJ, et al. Circumferential ablation of Barrett's esophagus that contains high-grade dysplasia: a U.S. multicenter registry. Gastrointest Endosc. 2008;68:35-40.

9. Velanovich V. Endoscopic endoluminal radiofrequency ablation of Barrett's esophagus: initial results and lessons learned. Surg Endosc. 2009;23:2175-80.

10. Lyday WD, Corbett FS, Kuperman DA, Kalvaria I, Mavrelis PG, Shughoury AB, et al. Radiofrequency ablation of Barrett's esophagus: outcomes of 429 patients from a multicenter community practice registry. Endoscopy. 2010;42:272-8.

11. Eldaif SM, Lin E, Singh KA, Force SD, Miller DL. Radiofrequency ablation of Barrett's esophagus: short-term results. Ann Thorac Surg. 2009;87:405-10. 
12. Korst RJ, Santana-Joseph S, Rutledge JR, Antler A, Bethala V, DeLillo A, et al. Effect of hiatal hernia size and columnar segment length on the success of radiofrequency ablation for Barrett's esophagus: a single-center, phase II clinical trial. J Thorac Cardiovasc Surg. 2011;142:1168-73.

13. Chandrasoma P, Wijetunge S, DeMeester S, Ma Y, Hagen J, Zamis L, et al. Columnar-lined esophagus without intestinal metaplasia has no proven risk of adenocarcinoma. Am J Surg Pathol. 2012;36:1-7.

14. Gray NA, Odze RD, Spechler SJ. Buried metaplasia after endoscopic ablation of Barrett's esophagus: a systematic review. Am J Gastroenterol. 2011;106:1899-908.

15. Vaccaro BJ, Gonzalez S, Poneros JM, Stevens PD, Capiak KM, Lightdale CJ, et al. Detection of intestinal metaplasia after successful eradication of Barrett's esophagus with radiofrequency ablation. Dig Dis Sci. 2011;56:1996-2000.

16. Di Pietro M, O'Donovan M, Fitzgerald RC. Where is the truth when it comes to cancer risk in Barrett's esophagus? Gastroenterology. 2012;142:1245-7.
17. Yachimski P, Falk GW. Subsquamous intestinal metaplasia: implications for endoscopic management of Barrett's esophagus. Clin Gastroenterol Hepatol. 2012;10:220-4

18. Peck-Radosavljevic M, Puspok A, Potzi R, Oberhuber G. Histologic findings after routine biopsy at the gastro-esophageal junction. Eur J Gastroenterol Hepatol. 1999;11:1265-70.

19. Felley C, Bouzourene H, VanMelle MBG, Hadengue A, Michetti P, Dorta G, et al. Age, smoking and overweight contribute to the development of intestinal metaplasia of the cardia. World J Gastroenterol. 2012;18:2076-83.

20. Veeramachaneni N. Radiofrequency ablation for nondysplastic Barrett's esophagus: should we do it, because we can? J Thorac Cardiovasc Surg. 2011;142: 1173-4.

21. Korst RJ, Lee BE. The use of radiofrequency ablation for patients with nondysplastic Barrett's esophagus. J Thorac Cardiovasc Surg. 2012;143:992-3. 